\title{
Late onset hereditary sensory and autonomic neuropathy with cognitive impairment associated with Y163X prion mutation
}

\author{
Andreas C. Themistocleous • Robin Kennett • \\ Masud Husain · Jacqueline Palace • \\ Simon Mead · David L. H. Bennett
}

Received: 31 July 2014/Revised: 25 September 2014/Accepted: 27 September 2014/Published online: 7 October 2014

(C) The Author(s) 2014. This article is published with open access at Springerlink.com

Dear Sirs,

A 69-year-old male presented with a 16-year history of numbness and paraesthesia of both feet and symptomatic postural hypotension. He reported episodes of painless thermal injuries to his limbs and lower urinary tract symptoms including reduced urinary flow, frequency, nocturnal incontinence and recurrent urinary tract infections. There was a long history of diarrhoea which preceded his sensory symptoms by 10 years and resulted in $20 \mathrm{~kg}$ of weight loss, and increasing memory difficulties with greatest difficulty in recalling recent events. His mother had suffered from symptomatic postural hypotension and foot ulceration developing in her sixth decade; she died in her seventh decade. It is not known whether she suffered from chronic diarrhoea or cognitive impairment. He has two brothers whom are unaffected.

Blood pressure was 156/92 lying and 79/53 standing. On neurological examination, cranial nerves were normal and there was mild wasting of the intrinsic foot muscles more marked on the right than the left. Tone and motor strength was normal. On sensory examination, pinprick was reduced to the mid-calf bilaterally, vibration sense was reduced to the knees, light touch to the ankles and joint position sense

A. C. Themistocleous $(\bowtie) \cdot$ R. Kennett · M. Husain · J. Palace ·

D. L. H. Bennett

Nuffield Department of Clinical Neurosciences, John Radcliffe

Hospital, Level 6, West Wing, Oxford OX3 9DU, UK

e-mail: andreas.themistocleous@ndcn.ox.ac.uk

\section{S. Mead}

Medical Research Council (MRC) Prion Unit, The National Prion Clinic, University College London (UCL) Institute of Neurology, Queen Square House, Queen Square,

London WC1N 3BG, UK

e-mail:simon.mead@uclh.nhs.uk was reduced at the hallux. His ankle jerk reflexes were absent. His gait was hesitant. He was unable to perform tandem gait and Romberg's sign was positive.

Neurophysiological studies are summarised in Table 1 and showed a length-dependant predominantly axonal motor and sensory peripheral neuropathy with subtle demyelinating features. Cognitive testing revealed impairment with major deficits, most prominently in memory and executive function. Table 2 summarises all remaining investigations. Of note is the absence of any evidence of systemic amyloid.

Genetic testing revealed a recently described Y163X truncation mutation of the gene encoding prion protein $(P R N P)$ [1]. Prion protein is tethered to the cell membrane via a glycosylphosphatidylinositol anchor and the Y163X mutation results in a premature stop codon such that the truncated prion protein is no longer membrane anchored. The PRNP Y163X mutation, follows an autosomal dominant inheritance pattern, presents with adult onset chronic diarrhoea, followed by symptoms of a mixed, predominantly sensory and autonomic neuropathy and late onset cognitive decline and seizures. Pathologically prion protein is deposited throughout peripheral organs primarily the bowel and peripheral nerves, either in between nerve fibres [1] or as ragged deposits in the myelin [2] with significant fibre loss and no evidence of demyelination, and the cortex in the form of amyloid plaques, amyloid angiopathy, tauopathy and unique prion protein fragments. Pan-autonomic failure and peripheral neuropathy is probably due to abnormal prion deposition within the peripheral nervous system. Direct toxic effects of prion protein, deposited in bowel and urinary bladder, may contribute to severe diarrhoea and urinary symptoms. We have not studied adjacent markers on chromosome 20 to define whether there is a common ancestor with the larger pedigree [1]. 
Table 1 Summary of neurophysiological studies

\begin{tabular}{|c|c|c|c|c|}
\hline \multirow[t]{2}{*}{ Motor studies } & \multicolumn{2}{|l|}{1997} & \multicolumn{2}{|l|}{2013} \\
\hline & Right & Left & Right & Left \\
\hline \multicolumn{5}{|l|}{ Nerve } \\
\hline \multicolumn{5}{|l|}{ Tibial } \\
\hline Latency (ms) & 5.8 & 5.4 & & 6.5 \\
\hline Amplitude (mV) & 0.8 & 1.1 & & 0.05 \\
\hline Conduction velocity $\mathrm{m} / \mathrm{s}$ & 36 & 36 & & \\
\hline F Wave $(\max ) \mathrm{ms}$ & 65.5 & Absent & & Absent \\
\hline \multicolumn{5}{|l|}{ Peroneal } \\
\hline Latency (ms): ankle & & & & 5.45 \\
\hline Amplitude (mV): ankle & & & & 0.3 \\
\hline Amplitude $(\mathrm{mV})$ : above knee & & & & 0.3 \\
\hline Conduction velocity $(\mathrm{m} / \mathrm{s})$ & & & & 30.5 \\
\hline F Wave $(\max ) \mathrm{ms}$ & & & & Absent \\
\hline \multicolumn{5}{|l|}{ Ulnar } \\
\hline Latency (ms): wrist & & & 3.30 & \\
\hline Amplitude $(\mathrm{mV})$ : wrist & & & 11.7 & \\
\hline Amplitude (mV): above elbow & & & 9.6 & \\
\hline Conduction velocity (m/s) & & & 45.6 & \\
\hline F Wave (min) ms & & & 33.15 & \\
\hline \multicolumn{5}{|l|}{ Median } \\
\hline Latency (ms): wrist & 4.3 & 3.90 & 3.75 & \\
\hline Amplitude (mV): wrist & 18.8 & 16.0 & 14.9 & \\
\hline Amplitude (mV): elbow & 17.3 & 14.8 & 7.1 & \\
\hline Conduction velocity $(\mathrm{m} / \mathrm{s})$ & 52 & 48 & 43.3 & \\
\hline F Wave (min) $\mathrm{ms}$ & & & 34.25 & \\
\hline \multirow[t]{2}{*}{ Sensory studies } & 1997 & & 2013 & \\
\hline & Right & Left & Right & Left \\
\hline
\end{tabular}

Nerve

Sural

Latency (peak) ms

Amplitude (peak-peak) $\mu \mathrm{V}$

Radial

Latency (onset) ms

Latency (peak) ms

Amplitude (peak-peak) $\mu \mathrm{V}$

Conduction velocity (onset) $\mathrm{m} / \mathrm{s}$

Ulnar

\section{Latency (peak) ms}

Amplitude (peak-peak) $\mu \mathrm{V}$

Median

Latency (peak) ms

Amplitude (peak-peak) $\mu \mathrm{V}$

$\begin{array}{llll}\begin{array}{l}\text { Absent } \\ \text { Absent }\end{array} & \begin{array}{l}\text { Absent } \\ \text { Absent }\end{array} & \begin{array}{l}\text { Absent } \\ \text { Absent }\end{array} & \begin{array}{l}\text { Absent } \\ \text { Absent }\end{array} \\ & & 1.90 & \\ 2.80 & 2.80 & 2.60 & \\ 10.0 & 10.0 & \mathbf{0 . 2 6} & \\ & & 44.7 & \text { Absent } \\ & 3.4 & \text { Absent } \\ 3.0 & \mathbf{1 . 0} & \text { Absent } & \text { Absent } \\ \mathbf{3 . 1} & 4.10 & \text { Absent } & \text { Absent } \\ 4.10 & \mathbf{2 . 1 0} & \text { Absent } & \\ \mathbf{2 . 2 0} & 2013 & & \\ \end{array}$

Electromyography

1997

2013

Muscle

Right tibialis anterior

No spontaneous activity, Normal pattern of motor unit recruitment with motor units up to $2.5 \mathrm{mV}$
No abnormal spontaneous activity. Voluntary recruitment moderately severely reduced in density with an excess of slightly unstable irregular motor unit potentials: durations up to $20 \mathrm{~ms}$, amplitude up to $10 \mathrm{mV}$ 
Table 1 continued

\begin{tabular}{lll}
\hline Electromyography & 1997 & 2013 \\
\hline Right first dorsal interosseous & $\begin{array}{c}\text { No spontaneous activity, Normal pattern of motor } \\
\text { unit recruitment with motor units up to } 2.5 \mathrm{mV}\end{array}$ \\
\hline
\end{tabular}

The neurophysiological studies were consistent with a length-dependant predominantly axonal motor and sensory peripheral neuropathy. However, the slowing of the conduction velocities, prolonged $\mathrm{F}$ waves and conduction block of the median nerve suggest a possible demyelinating component. Sympathetic skin response (performed only in 2013) was absent in the right hand and left foot

Bold values indicate abnormal results

$m s$ milliseconds, $m V$ millivolt, $\mathrm{m} / \mathrm{s}$ metres per second, $\mu V$ microvolt

Table 2 Summary of relevant investigations

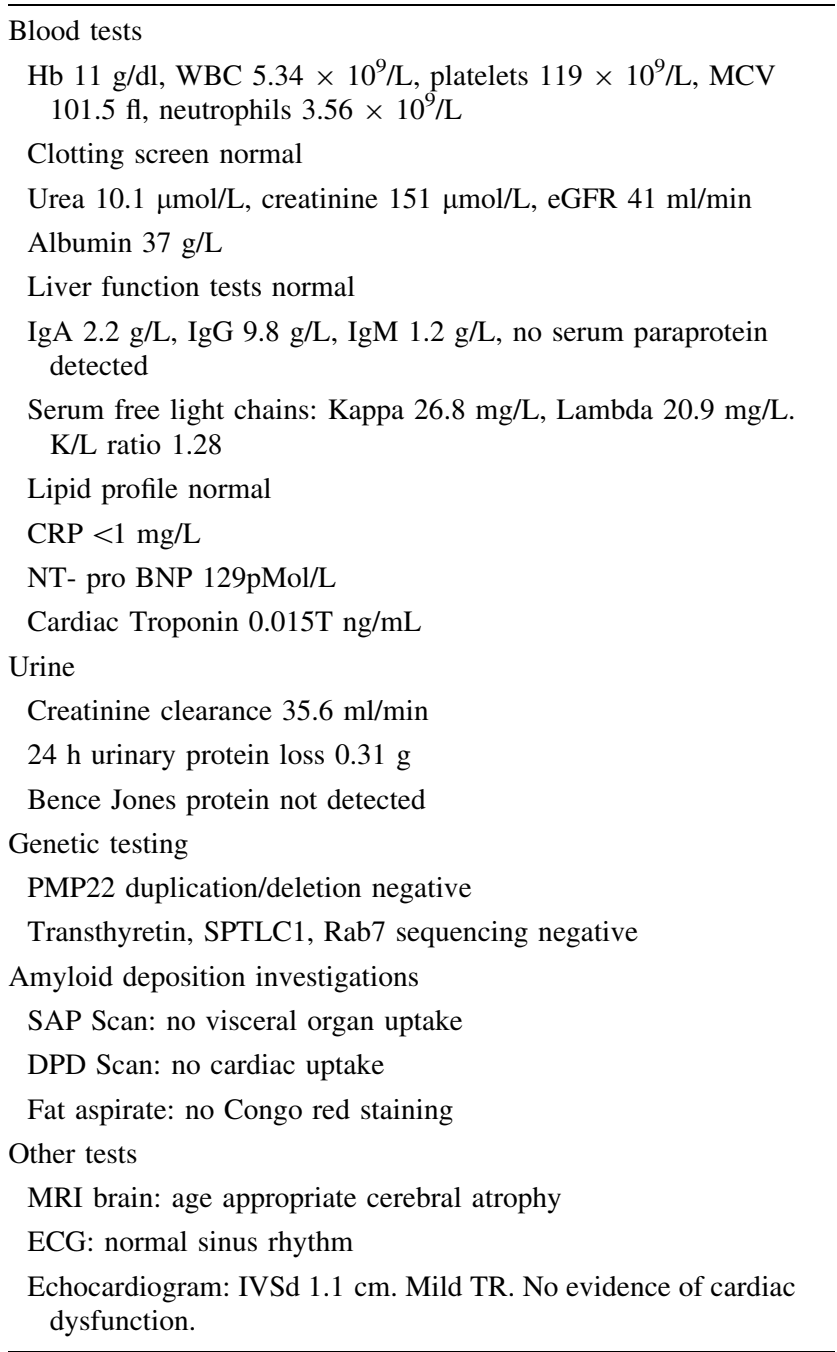

A 2-bp deletion in codon 178 of PRNP has been described in Japanese kindred causing a familial sensory and autonomic neuropathy with associated cognitive impairment [2]. A different insertional mutation of PRNP resulting in a truncation at position 163 has also been associated with hereditary sensory and autonomic neuropathy [3].
The clinical presentation of prion protein systemic amyloidosis caused by the PRNP Y163X mutation is distinct from previously described forms of hereditary sensory autonomic neuropathy [4] with prominent and early bladder and bowel symptoms, late onset sensory/autonomic neuropathy followed by cognitive involvement. The duration of symptoms and early onset of bowel dysfunction would also be atypical for amyloid neuropathy.

Interesting features of this case include some subtle demyelinating features noted on nerve conduction. Occasional cases of amyloid polyneuropathy have also been reported to show demyelinating changes [5]. Mild conduction slowing could represent direct toxicity of the prion protein on Schwann cells or even prion protein haploinsufficiency as axonal prion protein has been shown to be required for myelin maintenance in mouse models [6]. This case demonstrates the importance of PRNP analysis, which should be considered in the investigation of unexplained diarrhoea with a sensory neuropathy and is an important differential of familial amyloid polyneuropathy.

Conflicts of interest On behalf of all authors, the corresponding author states that there is no conflict of interest.

Ethical standard On behalf of all the authors, the corresponding author states that we acted in accordance with the ethical standards laid down in the 1964 Declaration of Helsinki.

Open Access This article is distributed under the terms of the Creative Commons Attribution License which permits any use, distribution, and reproduction in any medium, provided the original author(s) and the source are credited.

\section{References}

1. Mead S, Gandhi S, Beck J et al (2013) A novel prion disease associated with diarrhea and autonomic neuropathy. N Engl J Med 369:1904-1914. doi:10.1056/NEJMoa1214747

2. Matsuzono K, Ikeda Y, Liu W et al (2013) A novel familial prion disease causing pan-autonomic-sensory neuropathy and cognitive impairment. Eur J Neurol 20:e67-e69. doi:10.1111/ene.12089

3. Capellari S, Parchi P, Corrado P et al (2014) Prion disease associated with diarrhoea and autonomic neuropathy: phenotypic and genetic characterisation of an Italian family. Poster P.213 Prion, Trieste 
4. Auer-Grumbach M (2013) Hereditary sensory and autonomic neuropathies. Handb Clin Neurol 115:893-906. doi:10.1016/B9780-444-52902-2.00050-3

5. Mathis S, Magy L, Diallo L et al (2012) Amyloid neuropathy mimicking chronic inflammatory demyelinating polyneuropathy. Muscle Nerve 45:26-31. doi:10.1002/mus.22229
6. Bremer J, Baumann F, Tiberi C et al (2010) Axonal prion protein is required for peripheral myelin maintenance. Nat Neurosci 13:310-318. doi:10.1038/nn.2483 